\title{
Efeito fitoterápico in vitro de Rosmarinus officinalis e Origanum majorana frente a Staphylococcus aureus, isolado de mastite bovina
}

Brenda Tiradentes Tavares, Matheus Castro Franco, Mariana Paganini Lourencini , Mirian Alves Goldner, Gabriel Ricardo de Souza Lima, Dirlei Molinari Donatele, Lenir Cardoso Porfirio, Vinícius Borges Taquetti, Ítalo Câmara de Almeida, Felipe Berbari Neto

Centro de Ciências Agrarias e Engenharias, Universidade Federal do Espirito Santo (UFES), Vitória, ES, Brasil

*Autor correspondente

e-mail: berbarineto@hotmail.com

\section{Resumo}

Staphylococcus aureus é o principal agente patológico da mastite, inflamação da glândula mamária, entre outras infecções causadas por este microrganismo Gram-positivo, que pode levar o curso dessa e de outras doenças à cronicidade e torná-las mais difíceis de serem eliminadas. Faz-se necessário o estudo de novas alternativas que sejam capazes de eliminar esse patógeno e, consequentemente, a doença que causam, visto que boa parte dos antibióticos utilizados já não atua de forma eficaz na eliminação deste microrganismo. A resistência bacteriana é responsável pelo fracasso no tratamento de infecções com agentes quimioterápicos. Dentre alternativas de tratamento estão plantas utilizadas tradicionalmente na medicina popular, como a Rosmarinus officinalis e Origanum majorana, que são plantas conhecidas popularmente como "Alecrim" e "Manjerona", respectivamente, sendo duas das 71 espécies escolhidas pelo RENISUS (Relação Nacional de Plantas de interesse do SUS/ Sistema de Saúde Nacional Brasileiro), com prioridade para estudos farmacológicos. Há estudos científicos que comprovam algumas de suas propriedades como a ação antibiótica, antiinflamatória, antioxidante e diurética, no caso da R.officinalis, e antiespasmódica, expectorante, mucolítica, cicatrizante e digestiva no caso da O.majorana. 0 emprego de fitoterápicos , que tem sido uma alternativa de baixo custo e de ótimos resultados in vitro contra agentes patogênicos de várias doenças, apresenta-se como uma destas formas no combate à mastite, por não apresentar efeito maléfico quanto à presença de resíduos devido a sua característica biodegradável e boa atuação sobre microrganismos. Este experimento teve por finalidade avaliar a eficiência antimicrobiana in vitro do extrato hidroalcoólico (tintura) e do extrato glicólico das folhas de alecrim e manjerona nas concentrações de 1, 3, 5, 10, 25, 50, 75 e $100 \%$ contra o S. aureus, isolados de mastite clínica bovina, além do uso de cepa controlada, cedida pela Empresa de Pesquisa Agropecuária do Estado do Rio de Janeiro - PESAGRO (ATCC 6538). A sensibilidade da 
amostra foi considerada para medidas superiores a $12 \mathrm{~mm}$, de acordo com Silva (2003). Nos resultados dos antibiogramas, pode-se observar que as concentrações dos extratos de Origanum majorana. e Rosmarinu sofficinalis possuem ação inibitória in vitro sobre Staphylococcus aureus nas concentrações de 100\% dos extratos glicólicos; entretanto, não apresentaram resultados significativos nas demais concentrações nem tampouco em concentração alguma do extrato hidroalcoólico de ambos os fitoterápicos. 